\title{
Serum IgE Levels of Diarrheic Patients in Northwest Ethiopia with High Prevalence of HIV and Intestinal Parasitoses
}

Bemnet Amare $^{1 *}$, Yeshambel Belyhun², Beyene Moges ${ }^{2}$, Andargachew Mulu1,2, Fusao Ota ${ }^{3}$, Ketema Tafess ${ }^{2}$ and Afework Kassu²

${ }^{1}$ Department of Medical Biochemistry, College of Medicine and Health Sciences, University of Gondar, Gondar, Ethiopia

${ }^{2}$ Department of Microbiology, Immunology and Parasitology, College of Medicine and Health Sciences, University of Gondar, Gondar, Ethiopia

${ }^{3}$ Department of Preventive Environment and Nutrition, Graduate School of Nutrition and Bioscience, Institute of Health Biosciences, the University of Tokushima, Tokushima

770-8503, Japan

\begin{abstract}
Background: HIVIAIDS remains a major health problem in Sub-Saharan Africa. Co-infection with intestinal parasites has been suggested to worsen the outcome of infection by polarizing the immune response towards Th2. This study investigated the IgE profile in patients with diarrhea and with or without HIV and/or intestinal parasites co-infection at the time of diagnosis.
\end{abstract}

Methods and Materials: A cross-sectional study was conducted among diarrheic patients with and without HIV/ AIDS attending at the outpatient Department of the University of Gondar teaching hospital, in Gondar, Ethiopia. Stool samples were examined using standard parasitological procedures. The presence of HIV antibodies was determined by an enzyme linked immunosorbent assay following the manufacturer's instruction.

Results: Among tested diarrheic patients, 109 (52.9\%) of them were seropositive for HIV. Chronic and acute diarrheas were diagnosed in $114(55.3 \%)$ and $92(44.7 \%)$ of the patients, respectively. Intestinal parasites were detected in 30(27.5\%) among HIV seropositive and 36(37.1\%) of HIV seronegative diarrheic patients. Diarrhea and marked weight loss were found to be significantly associated with HIV infection $(\mathrm{P}<0.05)$. Median IgE concentration found in HIV positive diarrheic patients $(618 \mathrm{IU} / \mathrm{ml}$, IQR 107.25-971.25 IU/ml) was not significantly $(P>0.05)$ higher than in HIV negative diarrheic patients $(618 \mathrm{IU} / \mathrm{ml}$, IQR 304.50-739 IU/ml). Significantly higher association of median total IgE level was obtained in diarrheic male patients (624 IU/ml, IQR 325.50-857.25 IU/ml) than diarrheic female patients $(490 \mathrm{IU} / \mathrm{ml}$, IQR 39-835 IU/ml), P<0.001. Adjusted estimates of the effects of HIV, age, and helminth infection on IgE concentration, estimated using linear regression did not showed significant associations.

Conclusion: There was a remarkably elevated IgE response in diarrheic patients irrespective of HIV and/or intestinal parasitic infection. The correlation of lgE levels with parasitic infection with or without HIV co-infection as well the immunological and molecular mechanisms of IgE overproduction and its role in HIV infection needs further investigation.

Keywords: Northwest Ethiopia; HIV/AIDS; Diarrhea; Intestinal parasitoses; Total immunoglobulin E

\section{Introduction}

Diarrheal diseases are one of the most important causes of morbidity and mortality in developing countries [1]. The situation is severe in sub-Saharan Africa, a region where an estimated 25.8 million adults and children are infected with HIV [2]. Diarrhea, the passage of loose or watery stools at least three times in 24 hours, is one of the clinical manifestations of HIV infection and usually tends to be chronic [1]. Chronic diarrhea, an episode that begins acutely and lasts for more than four weeks [1] in tropical countries is associated with weight loss and is often the presenting illness of HIV infected individuals. This diarrhea wasting syndrome in association with a positive HIV serology test is an AIDS defining illness in the World Health Organization's classification [3].

In addition, parasitic infection of the intestinal tract is a major source of disease in patients with HIV particularly in the tropics, where specific pathogens are identified in more than half of the HIV/AIDS patients with persistent diarrhea [4].

Infection with intestinal parasites, mainly helminths, elicits Th2 immune response [5]. In sub Saharan Africa, where the prevalence of parasitic infections is very high, a dominant Th2 polarized immune response has been reported [6,7] and suggested to increase susceptibility to both intracellular pathogens like M. Tuberculosis and HIV. Co-infection also hastens progression of their disease [8-11]. Such an imbalance with an increase in Th2 cells favors IgE production [10] which may have clinical effects such as poor prognosis in co-infected individuals.

Reports on immunological interactions between IgE, intestinal parasitoses and HIV in Ethiopia is too little, a country where the prevalence of these infections is very high. Therefore, this study aimed to investigate the IgE profile in vivo in patients with diarrhea and with or without HIV and/or intestinal parasites co-infection at the time of diagnosis.

Corresponding author: Bemnet Amare, Department of Microbiology, Immunology and Parasitology, University of Gondar, PO Box 196, Gondar, Ethiopia, E-mail: amarebem6@gmail.com

Received December 11, 2011; Accepted January 15, 2012; Published January 19, 2012

Citation: Amare B, Belyhun Y, Moges B, Mulu A, Fusao Ota, et al. (2012) Serum IgE Levels of Diarrheic Patients in Northwest Ethiopia with High Prevalence of HIV and Intestinal Parasitoses. J AIDS Clinic Res 3:136. doi:10.4172/2155-6113.1000136

Copyright: ( 2012 Amare B, et al. This is an open-access article distributed unde the terms of the Creative Commons Attribution License, which permits unrestricted use, distribution, and reproduction in any medium, provided the original author and source are credited. 


\section{Patients and Methods}

\section{Study design and subjects}

In this cross-sectional study, consecutive diarrheic patients diagnosed at the outpatient department of the University of Gondar Hospital, Gondar, Ethiopia were included. Informed consent was obtained from all subjects and the study was approved by the Research Ethics Committee of the University.

\section{Stool examination}

Stool samples were collected and examined on three consecutive days by direct microscopy of samples in saline and iodine. Formalinether sedimentation concentration methods were also followed to detect the intestinal parasites [12]. Patients found positive for intestinal protozoa (Entamoeba histolytica and Giardia lamblia) were treated with metronidazole or tinidazole. However, such patients were excluded from the study as IgE response is different in protozoal infection than in worm infections. Subjects found positive for intestinal helminths were treated with broad spectrum anthelminthics such as mebendazole, praziquantel, thiabendazole, and niclosamide where appropriate.

\section{Blood collection and screening for HIV}

After appropriate pretest counseling, venous blood was collected from each patient before initiation of therapy, and in a sub sample of them at the end of intensive phase of anti-TB chemotherapy. Serum was separated by centrifugation within two hours of collection and kept at $-20^{\circ} \mathrm{C}$ until used. The presence of HIV antibodies was determined by an enzyme linked immunosorbent assay following the manufacturer's instruction (Vironostica HIV Uni-Form II plus O, Organon Teknika, Boxtel, the Netherlands).

\section{Serum IgE determination}

The serum IgE levels were quantified by total IgE ELISA kit (IBL Immunobiological Laboratories, Hamburg, Germany) following the manufacturer's instructions. In brief, $10 \mathrm{ml}$ serum samples or standard IgE were pipetted in duplicates into wells of micro-titer plates precoated with monoclonal mouse antihuman IgE antibody together with peroxidase conjugated antihuman IgE. After incubation for 30 minute at room temperature the plates were rinsed with diluted wash buffer to remove unbound material. Then a substrate solution (tetramethylbenzidine) was pipette and incubated for 15 minute to induce development of color. The reaction was terminated by the addition of stop solution and the resulting dye was measured in a spectrophotometer (Model 680 Micro plate Reader, Bio-Rad Laboratories Inc., Japan) at a wave length of $450 \mathrm{~nm}$ against the substrate blank. The IgE concentration of the samples was read from a standard curve. Mean values of two separate determinations from each sample was used as serum IgE level of a particular study subject.

\section{Statistical analysis}

Total IgE levels were expressed as arithmetic or geometric mean and IU/ml. As total serum IgE levels were highly skewed, a logarithmic transformation $(\log 10)$ was performed to obtain a Gaussian shape. Correlations were made using Spearman's correlation analysis. The difference of total IgE between two groups was computed using nonparametric Mann Whitney $U$ test. A multivariate linear regression analysis was used to determine the effect of different factors on log (lgE). P-value less than 0.05 were accepted as significant. Statistical computations were performed using Statistical Package for Social Sciences (SPSS).

\begin{tabular}{|c|c|c|c|c|}
\hline \multicolumn{2}{|c|}{ Parameter } & Total & HIV+ (n=109) n (\%) & HIV- $(n=97) n(\%)$ \\
\hline \multirow{2}{*}{ Age } & $<35$ & $136(66.9)$ & $65(59.6)$ & $71(73.2)$ \\
\hline & $>35$ & $70(34.0)$ & $44(40.4)$ & $26(26.8)$ \\
\hline \multirow{2}{*}{ Sex } & Male & 127(61.7) & $65(59.6)$ & 62(63.9) \\
\hline & Female & $79(38.3)$ & $44(40.4)$ & $35(36.1)$ \\
\hline \multirow{2}{*}{ Address } & Rural & 142(68.9) & $78(71.6)$ & $64(66.0)$ \\
\hline & Urban & $64(34.1)$ & $31(28.4)$ & $33(34.0)$ \\
\hline \multirow{3}{*}{$\begin{array}{l}\text { Marital } \\
\text { Status }\end{array}$} & Married & $100(48.5)$ & $53(48.6)$ & $47(48.5)$ \\
\hline & Single & $77(37.4)$ & $33(30.3)$ & $44(45.4)$ \\
\hline & Divorced & $29(14.1)$ & 23(21.1) & $6(6.2)$ \\
\hline \multirow{5}{*}{ Occupation } & $\begin{array}{l}\text { Government } \\
\text { Employee }\end{array}$ & $47(22.8)$ & $25(22.9)$ & $22(22.7)$ \\
\hline & Farmer & $63(30.6)$ & $46(42.2)$ & $17(17.5)$ \\
\hline & Student & $27(13.1)$ & $17(15.6)$ & 10(10.3) \\
\hline & Housewife & 39(18.9) & $7(6.4)$ & $32(33.0)$ \\
\hline & Other & $30(14.6)$ & $14(12.8)$ & $16(16.5)$ \\
\hline \multirow{3}{*}{ Income* } & Low & $126(61.2)$ & $59(54.1)$ & $67(69.1)$ \\
\hline & Medium & $53(25.7)$ & $34(31.2)$ & 19(19.6) \\
\hline & High & $27(13.1)$ & $16(14.7)$ & $11(11.3)$ \\
\hline \multirow{2}{*}{ Diarrhea } & Acute & 92(44.7) & $60(55)$ & $32(33)$ \\
\hline & Chronic & 114(55.3) & $49(45)$ & $65(67)$ \\
\hline \multirow{2}{*}{ Weight loss } & Yes & $18(42.7)$ & $60(55)$ & $28(28.9)$ \\
\hline & No & 188(57.3) & $49(45)$ & $69(71.1)$ \\
\hline \multirow{2}{*}{$\begin{array}{l}\text { Intestinal } \\
\text { Parasitosis }\end{array}$} & Yes & $66(32.0)$ & $30(27.5)$ & $36(37.1)$ \\
\hline & No & $140(68.0)$ & $79(72.5)$ & 61(62.9) \\
\hline \multicolumn{3}{|l|}{ Mean IgE† } & $585.23 \pm 447.16$ & $597.32 \pm 388.97$ \\
\hline
\end{tabular}

†Mean \pm SD.

* Low: less than 1000 Ethiopian Birr/month. Medium: 1000 - 5000 Ethiopian Birr, High: more than 5000 Ethiopian Birr/month.

1 Ethiopian Birr $=0.12$ US Dollar (at the time of data collection)

Table 1: Demographic and clinical data of diarrheic patients included in the study by their HIV status $(n=206)$.

\begin{tabular}{|l|c|c|}
\hline \multirow{2}{*}{\multicolumn{1}{|c|}{ Parasite }} & \multicolumn{2}{c|}{ HIV status } \\
\cline { 2 - 3 } & Positive N (\%) & Negative N (\%) \\
\hline Entamoeba histolytica & $8(23.5)$ & $12(27.3)$ \\
\hline Giardia lamblia & $3(8.8)$ & $9(20.5)$ \\
\hline Strongyloides stercoralis & $9(26.5)$ & $3(6.8)$ \\
\hline Ascaris lumbricoides & $6(17.6)$ & $8(18.2)$ \\
\hline Hookworm & $3(8.8)$ & $5(11.4)$ \\
\hline Schistosoma mansoni & $3(8.8)$ & $5(11.4)$ \\
\hline Cryptosporidium spp. & $2(5.9)$ & $2(4.5)$ \\
\hline
\end{tabular}

Table 2: Type and frequency of intestinal parasites in diarrheic patients by HIV status.

\section{Results}

Two hundred and six diarrheic patients were included in the study. Demographic and clinical data of the patients were presented in Table 1. Majority of the patients were males 127(61.7\%). One hundred thirty six $(66.0 \%)$ of the patients were younger than 35 years old. One hundred and nine $(52.9 \%)$ of the diarrheic patients were seropositive for HIV. Chronic and acute diarrheas were diagnosed in 114(55.3\%) and $92(44.7 \%)$ of the patients, respectively. Intestinal parasites were detected in $30(27.5 \%)$ of the 109 HIV seropositive, two patients was found to have mixed infections and 36(37.1\%) of HIV seronegative diarrheic patients with four mixed infections. The prevalence including multiple infections from individual subjects and species of intestinal parasites detected in the patients is shown in Table 2.

The risk of HIV infection was associated with urban residence $(\mathrm{OR}=$ 
Citation: Amare B, Belyhun Y, Moges B, Mulu A, Fusao Ota, et al. (2012) Serum IgE Levels of Diarrheic Patients in Northwest Ethiopia with High Prevalence of HIV and Intestinal Parasitoses. J AIDS Clinic Res 3:136. doi:10.4172/2155-6113.1000136

Page 3 of 5

$1.98,95 \% \mathrm{CI}=0.98-3.99)$ and age $(\mathrm{OR}=1.98,95 \% \mathrm{CI}=1.02-3.86)$. There was no significant difference in the clinical presentation of intestinal parasitosis between HIV-seropositive and seronegative patients $(\mathrm{P}>$ $0.1)$. However, chronic diarrhea $(\mathrm{OR}=2.49,95 \% \mathrm{CI}=1.30-4.78)$ and marked weight loss $(\mathrm{OR}=2.61,95 \% \mathrm{CI}=1.40-4.87)$ were found to be significantly associated with HIV infection $(\mathrm{P}<0.05)$ (Table 3$)$.

Median IgE concentration found in HIV positive diarrheic patients (618 IU/ml, IQR 107.25-971.25 IU/ml) was not significantly higher than in HIV negative diarrheic patients $(618 \mathrm{IU} / \mathrm{ml}$, IQR 304.50-739 $\mathrm{IU} / \mathrm{ml}$ ), $P=0.3$ (Table 4 ). It was also not significantly higher in patients infected with intestinal parasites than in those without intestinal helminths in HIV seronegative diarrheic patients, $P=0.3$ (Table 4). But, significantly higher association of median total IgE level was obtained in diarrheic male patients (624 IU/ml, IQR 325.50-857.25 $\mathrm{IU} / \mathrm{ml}$ ) than diarrheic female patients (490 IU/ml, IQR 39-835 IU/ml), $(P<0.001)$. Adjusted estimates of the effects of HIV, age, residence area and helminth infection on $\operatorname{IgE}$ concentration, estimated using linear regression including all these variables, were not significantly different from those in Table 4.

\section{Discussion}

The immune profile of individuals living in sub Saharan Africa is characterized by a background of chronic immune activation which has been attributed to exposure to high load of environmental antigens [7-10]. Such exposure has been suggested to impair the host's immune response to HIV and intestinal parasitosis [8] which is highly prevalent in that part of the world $[13,14]$.

The present study was conducted in a tropical country, in sub Saharan Africa, where the prevalence of intestinal parasites, HIV is amongst the highest in the world [15-17]. The results of the study indicated that the level of serum IgE was remarkably high in diarrheic patients. In addition it was revealed that serum IgE was higher in patients irrespective of HIV and/or intestinal parasites.

From HIV positive patients with diarrhea, $55 \%$ and $45 \%$ had acute and chronic diarrhea, respectively. Enteric pathogens were detected in 30 (27.5) of the 109 patients: 28 patients harboured a single pathogen, and 2 patients had mixed pathogens. Stools of all HIV-positive patients with diarrhea should thoroughly be investigated to identify etiologic agents for proper management; given that, diarrhea is frequently found

\begin{tabular}{|c|c|c|c|c|c|}
\hline \multicolumn{2}{|c|}{ Parameter } & \multirow{2}{*}{$\begin{array}{l}\text { HIV+ }(n=109) \\
65\end{array}$} & \multirow{2}{*}{\begin{tabular}{|l} 
HIV- $(\boldsymbol{n}=\mathbf{9 7})$ \\
71
\end{tabular}} & \multirow{2}{*}{\begin{tabular}{|l|} 
OR $(95 \% \mathrm{CI})$ \\
1
\end{tabular}} & \multirow[t]{2}{*}{ Multivariate OR $(95 \% \mathrm{Cl})$} \\
\hline Age & $<35$ & & & & \\
\hline & $>35$ & 44 & 26 & $1.849(1.025,3.335)$ & $1.979(1.015,3.857)^{\star}$ \\
\hline \multirow[t]{2}{*}{ Sex } & Male & 65 & 62 & 1 & 1 \\
\hline & Female & 44 & 35 & $1.199(0.682,2.108)$ & $1.180(0.639,2.180)$ \\
\hline \multirow[t]{2}{*}{ Address } & Rural & 78 & 64 & 1 & 1 \\
\hline & Urban & 31 & 33 & $1.297(0.718,2.343)$ & $1.976(0.979,3.986)^{*}$ \\
\hline \multirow[t]{2}{*}{ Marital Status } & Married & 53 & 47 & 1 & 1 \\
\hline & Un married & 56 & 50 & $0.993(0.575,1.717)$ & $1.306(0.685,2.488)$ \\
\hline \multirow[t]{2}{*}{ Diarrhea } & Acute & 60 & 32 & 1 & 1 \\
\hline & Chronic & 49 & 65 & $2.487(1.411,4.385)$ & $2.492(1.298,4.784)^{*}$ \\
\hline \multirow[t]{2}{*}{ Weight loss } & Yes & 60 & 28 & 1 & 1 \\
\hline & No & 49 & 69 & $3.017(1.691,5.384)$ & $2.606(1.395,4.869)^{*}$ \\
\hline \multirow[t]{2}{*}{ Intestinal Parasitosis } & Yes & 30 & 36 & 1 & 1 \\
\hline & No & 79 & 61 & $1.554(0.863,2.799)$ & $1.535(0.814,2.896)$ \\
\hline
\end{tabular}

${ }^{*} \mathrm{P}<0.05$

OR, Odds Ratio; Cl, Confidence Interva

Table 3: The association of some risk factors with HIV infections.

\begin{tabular}{|c|c|c|c|c|}
\hline \multicolumn{2}{|c|}{ Variables } & \multirow{2}{*}{$\begin{array}{l}\text { Median and IQR } \\
618(198-739)\end{array}$} & \multirow{2}{*}{$\begin{array}{l}\text { OR }(95 \% \mathrm{Cl}) \\
1\end{array}$} & \multirow{2}{*}{$\begin{array}{l}p \text {-value } \\
0.7\end{array}$} \\
\hline Age & $<35$ & & & \\
\hline Rye & $>35$ & 618(149.75-1028) & $1.112(0.506-2.441)$ & \\
\hline \multirow{2}{*}{ Sex } & Male & $624(325.50-857.25)$ & 1 & $<0.001$ \\
\hline & Female & $490(39-835)$ & $0.310(0.151-0.639)^{*}$ & \\
\hline \multirow{2}{*}{ Address } & Rural & $611(159-786)$ & 1 & 0.7 \\
\hline & Urban & 735(307.75-929.25) & $0.864(0.373-2.000)$ & \\
\hline \multirow{2}{*}{ Marital Status } & Married & 618(235.75-999.25) & 1 & 0.9 \\
\hline & Un married & $614(149.50-739)$ & $1.039(0.490-2.200)$ & \\
\hline \multirow[t]{2}{*}{ Diarrhea } & Acute & 618(178-835) & 1 & 0.6 \\
\hline & Chronic & 613(197.50-861) & $1.220(0.556-2.677)$ & \\
\hline \multirow{2}{*}{ Weight loss } & Yes & 618(107.25-883.75) & 1 & 0.5 \\
\hline & No & 612(241-791.50) & $0.805(0.379-1.711)$ & \\
\hline \multirow{2}{*}{ Intestinal Parasitosis } & Yes & $624(322.75-837.25)$ & 1 & 0.3 \\
\hline & No & $611(145-844)$ & $0.695(0.313-1.545)$ & \\
\hline \multirow{2}{*}{ HIV status } & Positive & $618(107.25-971.25)$ & 1 & 0.3 \\
\hline & Negative & $618(304.50-739)$ & $1.420(0.658-3.067)$ & \\
\hline
\end{tabular}

${ }^{*} \mathrm{P}<0.05$

OR, Odds Ratio; $\mathrm{Cl}$, Confidence Interval.

Table 4: Median and interquartile ranges (IQR) for total lgE. 
in HIV infection with different clinical stages [18-20]. According to the result of this study; urban residence, age above 35 years old, diarrhea and marked weight loss were significantly associated with HIV infection [21-23].

Intestinal parasitic infections were found to be more prevalent in the rural area and mostly male study subjects were infected. The rarity of infection by multiple parasite species was also notable. Although it is documented that the sensitivity of a single stool examination is only about $40 \%$ [24], in most comparable studies in similar developing communities only a single stool sample was examined. Part of the explanation may be an improvement in personal hygiene over the past decades. It is also possible that there has been an increase in the treatment of helminth infections over time in our study communities. Worms are held responsible for all manner of constitutional upsets and use of deworming medicines, which can be freely bought from local drug stores, is very common. The higher prevalence of parasite infections in the rural area could be partly explained by the season of collection since parasitic infections are more common during the wet season [25].

In the present study, significantly higher IgE levels were observed irrespective of HIV sero-status and patients co-infected with intestinal helminths compared to non-infected individuals. This is due to the fact that, intestinal parasitic infections are potent stimulators of IL-4 dependent synthesis of both parasites specific IgE, which is important in the host immune response to parasites, and polyclonal IgE [26]. Parasite specific IgE attaches to high affinity Fc receptors on mast cells, and neighboring specific immunoglobulin cross-link and trigger mast cell degranulation. This process mediates an anti-parasite response via the release of pro-inflammatory cytokines [27]. This mechanism has been suggested as the major cause of the elevated serum levels of IgE in tropical populations where the prevalence of parasites is very high [28].

In this study, the mean IgE level was increased in most of diarrheic patients irrespective of HIV and intestinal parasitic infection patients and the serum IgE levels were not significantly associated to Age, address, duration of diarrhea. This result was not in line with previous studies on the relationship between IgE and HIV in Western countries which demonstrates the possibility that serum IgE level increases along with the severity of the disease in patients with HIV infection $[29,30]$. It may due to the fact that, elevated total serum IgE levels also occur in patients with a variety of allergic diseases and non-allergic diseases, including viral infections, atopic dermatitis, and neoplastic disease such as Hodgkin's lymphoma and IgE myeloma [31]. However, this study did not include an exhaustive search for those pathological conditions.

On multiple linear regression analysis, male diarrheic patients $(P<0.001)$ were independently associated with increased serum IgE levels. Multiple studies have shown that IgE level was elevated in parasite infected patient and mostly male study subjects were infected with parasite $[32,33]$. There might be a possibility that the higher IgE level found in male was due to a higher ratio of parasite infection in male which is similar to previous report in Ethiopia [35]. The reason for higher intestinal parasitic infection prevalence is not clear but as to schistosomiasis, males may have higher exposure to river water than females. Some parasitologists also suggest that susceptibility to parasitic infections is greater in males and may contribute to male biased mortality [36]. IgE level is also affected by smoking history [37], in Ethiopia male smokers are higher than female smokers [38-39]. In line with our findings, the work of Johnson et al. [34] compared total and allergen specific IgE by gender from birth through 4 years of age and found that total IgE increased with age for boys and girls and was higher in boys. This suggested that differences in IgE development between young boys and girls may partially account for the higher prevalence of asthma in boys than in girls.

The main limitation of this study however is that serum $\operatorname{IgE}$ level of the patients with out diarrhea was not documented to make comparisons. The relationship between worm burden and levels of IgE was not also documented due to the nature of study design.

Taken together, the results of this study indicated that, there was a remarkably elevated IgE response in patients irrespective of HIV and/ or intestinal parasitic infection; although, this is a small group of study subjects and by no means be representative of the entire Ethiopian population, the findings may be used as a tool to assist further studies in this area. The correlation of IgE level with parasitic infection with or without HIV co infection needs further prospective clinicoepidemiological studies by including non diarrheic subjects. The results suggest further study of IgE response in diarrheic patients in Ethiopia relative to infections other than HIV and on the molecular mechanisms of IgE overproduction and its role in HIV infection are also needed.

\section{Acknowledgements}

This work was supported in part by a Grants-in Aid (Nos. 11691211 and 14657017) from the Ministry of Education, Culture, Sports, Science and Technology of Japan, and also partly supported by a grant from Yakult Ltd, Japan and the Gondar University, Ethiopia. The authors are grateful to Dr. Aya Takeoka for technical help.

\section{References}

1. Kosek M, Bern C, Guerrant RL (2003) The global burden of diarrhoeal disease as estimated from studies published between 1992 and 2000. Bull World Health Organ 81: 197-204.

2. Joint United Nations Program on HIVIAIDS/ World Health Organization (UNAIDS/WHO) (2005) AIDS epidemic update.

3. Thomas PD, Forbes A, Green J, Howdle P, Long R, et al. (2003) Guidelines for the investigation of chronic diarrhea. Gut 52: v1- v15

4. World Health Organization (1986) Provisional WHO clinical case definition for AIDS. Wkly Epidemiol Rec 10: 303-306

5. Mosmann TR, Cherwinski H, Bond MW, Giedlin MA, Coffman RL (1986) Two types of murine helper T cell clone. 1. Definition according to profiles of lymphokine activities and secreted proteins. J Immunol 136: 2348-2357.

6. Constant SL, Bottomly K (1997) Induction of Th1 and Th2 CD4+ T cells responses: the alternative approaches. Ann Rev Immunol 15: 297-322.

7. Bentwich Z, Kalinkocich A, Weisman Z (1995) Immune activation is a dominant factor in the pathogenesis of African AIDS. Immunol Today 16: 187-191.

8. Bentwich Z, Kalinkocich A, Weisman Z, Borkow G, Beyers N, et al. (1999) Can eradication of helminthic infections change the face of AIDS and tuberculosis? Immunol Today 20: 485-487.

9. Borkow G, Weisman Z, Leng Q, Stein M, Kalinkovich, et al. (2001) A Helminths human immunodeficiency virus and tuberculosis. Scand J Infect Dis 33: 568571.

10. Fincham JE, Markus MB, Adams VJ (2003) Could control of soil-transmitted helminthic infection influence the HIVIAIDS pandemic. Acta Trop 86: 315-333.

11. Beaver PC, Jung RC, Cupp EW (1984) Examination of Specimens for Parasites: Clinical Parasitology. Lea and Fabiger, Philadelphia.

12. World Health Organization (1991) Basic laboratory methods in medica Parasitology

13. Corbett EL, Watt CJ, Walker N, Maher D, Williams BG, et al. (2003) The growing burden of tuberculosis. Global trends and interactions with the HIV epidemic. Arc Intern Med 163: 1009-1021. 
Citation: Amare B, Belyhun Y, Moges B, Mulu A, Fusao Ota, et al. (2012) Serum IgE Levels of Diarrheic Patients in Northwest Ethiopia with High Prevalence of HIV and Intestinal Parasitoses. J AIDS Clinic Res 3:136. doi:10.4172/2155-6113.1000136

Page 5 of 5

14. Kloos H, Tesfayohaness TM (1993) Intestinal parasites in Ethiopia: The ecology of health and disease in Ethiopia. Oxford: West view Press.

15. UNAIDS/WHO (2003) Reports on the Global AIDS epidemic.

16. UNAIDS (2007) Report on the Global AIDS Epidemic.

17. WHO (1987) Prevention and Control of Intestinal parasitic Infections. WHO Tech Rep Ser 749: 1-86.

18. Weber R, Ledergerber B, Zbinden R, Altwegg M, Pfyffer GE, et al. (1999) For the Swiss HIV Cohort Study. Enteric infections and diarrhoea in HIV -infected persons. Arch Intern Med 159: 1473-1480.

19. Brink AK, Mahé C, Watera C, Lugada E, Gilks C, et al. (2002) Diarrhea, CD4 counts and enteric infections in a community-based cohort of HIV-infected adults in Uganda. J Infect 45: 99-106.

20. Cranendonk RJ, Kodde CJ, Chipeta D, Zijlstra EE, Sluiters JF (2003) Cryptosporidium parvum and Isospora belli infections among patients with and without diarrhoea. East Afr Med J 80: 398-401.

21. Cohen D (1998) Poverty and HIVIAIDS in sub-Saharan Africa. UNDP Issue Paper.

22. Ohl M, Tate J, Duggal M, Skanderson M, Scotch M, et al. (2010) Rura Residence Is Associated With Delayed Care Entry and Increased Mortality Among Veterans With Human Immunodeficiency Virus Infection. Med Care 48: 1064-1070.

23. Amornkul PN, Vandenhoudt $H$, Nasokho P, Odhiambo F, Mwaengo D, et al. (2009) HIV Prevalence and Associated Risk Factors among Individuals Aged 13-34 Years in Rural Western Kenya. PLoS One 4: e6470.

24. Kang G, Mathew MS, Rajan DP, Daniel JD, Mathan MM, et al. (1998) Prevalence of intestinal parasites in rural Southern Indians. Trop Med Intl Health 3: 70-75.

25. Knight R, Merrett TG (1981) Hookworm infection in rural Gambia: seasona changes, morbidity and total IgE levels. Ann Trop Med Parasitol 75: 299-314.

26. Lynch NR (1987) Immediate hypersensitivity reactions to intestinal helminthic infections: Bailliere's Clinical Tropical Medicine and Communicable Diseases. Bailliere Tindall, London.

27. Else KJ, Finkelman FD (1998) Intestinal nematode parasites, cytokines and effector mechanisms. Int J Parasitol 28: 1145-1158.
28. Bentwich A, Weisman Z, Moroz C, Bar-Yehuda S, Kalinkovich A (1996) Immune dysregulation in Ethiopian immigrants in Israel: relevance to helminthic infections? Clin Exp Immunol 103: 239-243.

29. Wright DN, Nelson RP, Ledford DK, Fernandez-Caldas E, Trudeau WL, et al. (1990) Serum IgE and human immunodeficiency virus (HIV) infection. J Allergy Clin Immunol 85: 445-452.

30. Israel-Biët D, Labrousse F, Tourani JM, Sors H, Andrieu JM, et al. (1992) Elevation of IgE in HIV- infected subjects: a marker of poor prognosis. J Allergy Clin Immunol 89: 68-75.

31. Ownby DR (1993) Clinical significance of IgE: Allergy: principles and practice. (4thedn), Mosby, St. Louis.

32. Tsukioka K, Toyabe S, Akazawa K (2010) Total and specific IgE levels in adolescents and adults with bronchial asthma. Nihon Kokyuki Gakkai Zassh 48: 409-418.

33. Small CB, McGowan JP, Klein RS, Schnipper SM, Chang CJ, et al. (1998) Serum IgE levels in patients with Human Immunodeficiency Virus. Ann Allergy Asthma Immunol 81: 75-80.

34. Amare M, Gebre-Selassie S, Kassa T (2007) Prevalence of intestinal parasitic infections among urban dwellers in southwest Ethiopia. Ethiop $\mathrm{J}$ Health Dev 21: 12-17.

35. Owens IP (2002) Sex differences in mortality rate. Science 297: 2008-2009.

36. Oryszczyn MP, Annesi-Maesano I, Charpin D, Paty E, Maccario J, et al (2000) Relationships of active and passive smoking to total IgE in adults of the Epidemiological Study of the Genetics and Environment of Asthma, Bronchial Hyper responsiveness, and Atopy. Am J Respir Crit Care Med 161: 1241-1246.

37. Rudatsikira E, Abdo A, Muula AS (2007) Prevalence and determinants of adolescent tobacco smoking in Addis Ababa, Ethiopia. BMC Public Health 7 : 176

38. Hyman I, Fenta H, Noh S (2008) Gender and the smoking behaviour of Ethiopian immigrants in Toronto. Chronic Dis Can 28: 121-127.

39. Johnson CC, Peterson EL, Ownby DR (1998) Gender differences in total and allergen-specific IgE concentrations in a population based cohort from birth to age four years. Am J Epidemiol 147: 1145-1152. 